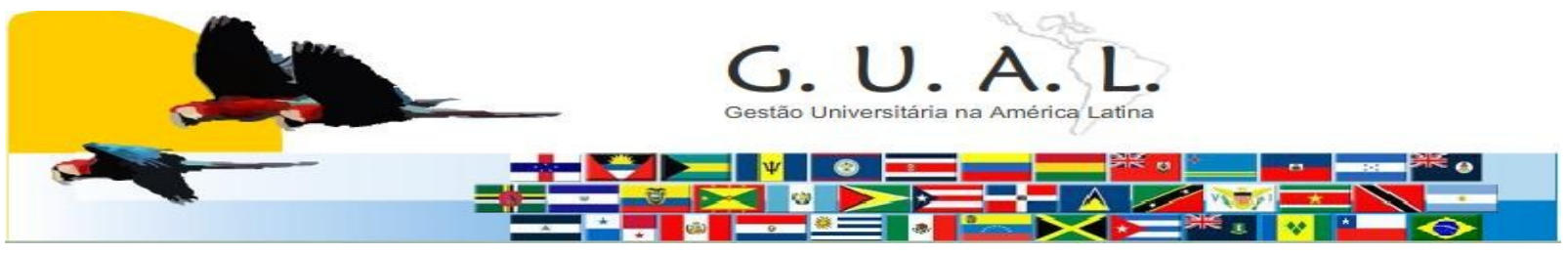

ISSN 1983-4535

\title{
A EDUCAÇÃO A DISTÂNCIA COMO ELO DE INTEGRAÇÃO E DE DESENVOLVIMENTO PARA OS INTEGRANTES DO MERCOSUL
}

Lucas Ambrósio Bezerra de Oliveira, Bacharel

Universidade Federal do Rio Grande do Norte - UFRN

lucasambro@gmail.com

Fernanda Cristina Barbosa Pereira Queiroz, Doutora Universidade Federal do Rio Grande do Norte - UFRN fernandacbpereira@yahoo.com.broufbp@ufrnet.br
Hélio Roberto Hékis, Doutor

Universidade Federal do Rio Grande do Norte - UFRN hrhekis@hotmail.com

Ricardo Pires de Souza, Bacharel

Universidade Federal do Rio Grande do Norte - UFRN ripiso@gmail.com

Jamerson Viegas Queiroz, Doutor

Universidade Federal do Rio Grande do Norte - UFRN

jvqjamerson@yahoo.com.broujvq@ufrnet.br

\section{RESUMO}

A educação é considerada como o elemento de maior relevância para o crescimento das nações, sendo portanto, um fator crítico para o desenvolvimento das mesmas. Destarte, o artigo tem como objetivo analisar a importância da educação a distância como elo de integração e desenvolvimento para os países membros do MERCOSUL. Trata-se de um ensaio teórico. Logo, como parâmetros à reflexão, dados e informações foram coletados em estudos científicos, nas principais organizações internacionais, projetos desenvolvidos em outros blocos econômicos, além de dados obtidos nos países do MERCOSUL. Os resultados do estudo apontam que o estimulo à criação de um programa integrado para expansão da educação a distância no MERCOSUL é de extrema importância e tem grande potencial, na qual se vislumbra um amplo desenvolvimento. Destaca-se que tal programa deve considerar uma educação que contemple as características locais, observando às questões regionais e globais, estimulando, portanto, a formação de cidadãos com comprometimento mundial. Conclui-se que a EAD pode contribuir com a integração e desenvolvimento das nações, assim como a internacionalização de Instituições de Ensino, por meio de intercâmbio de estudantes, professores e servidores, dentre outras vantagens.

Palavras-chave: Educação a distancia. MERCOSUL. Desenvolvimento. 


\section{INTRODUÇÃO}

Com a globalização da economia, a criação de blocos econômicos tornou-se uma tendência mundial. Um dos objetivos desses blocos é facilitar as relações comerciais dos países membros, adotando estratégias de redução de impostos, tarifas alfandegárias, chegando, em alguns casos, a haver isenção delas. Além das interações comerciais e econômicas, os blocos proporcionam outros benefícios como: integração social, produtiva, energética, livre trânsito da população, dentre outros itens que variam de acordo com as características de cada bloco econômico.

Na América do Sul, o MERCOSUL (Mercado Comum do Sul) é um dos blocos de maior destaque. Em 1991, a Argentina, o Brasil, Paraguai e Uruguai assinaram o Tratado de Assunção, vislumbrando a criação do bloco econômico, o qual foi consolidado em 1994 com o Protocolo de Ouro Preto, que estabeleceu a estrutura institucional do bloco, dotando-o com personalidade jurídica internacional.

No MERCOSUL, além dos objetivos básicos de um bloco (comerciais e econômicas), outros objetivos e protocolos de intenções foram propostos, assinados e incorporados pelos países membros. Um dos protocolos, assinados entre os Ministros da Educação, instituiu o SEM - Setor Educacional do MERCOSUL, por considerarem que "a educação deve acompanhar os processos de integração regional, para enfrentar, como bloco geocultural, os desafios decorrentes da transformação produtiva, dos avanços científico-tecnológicos e da consolidação da democracia” (MERCOSUR/RME/Acta No 01/92, p. 1).

Essa percepção é, também, observada no meio organizacional, onde gestores e empresários, de todo mundo, reforçam a importância da educação para o desenvolvimento das nações/organizações, chegando a ser discurso comum a importância que a educação confere ao desenvolvimento das mesmas. Fica evidente que a preocupação com desenvolvimento social, econômico, ambiental (dentro outros) dos países e, consequentemente, das organizações, passa pelo nível de educação da população.

Destarte, evidencia-se a importância de educação como elo de integração entre os povos do MERCOSUL. Contudo, sabe-se que existem uma série de problemas que envolvem a educação (qualidade do ensino, a acessibilidade, dentre outras). Como alternativa, emerge o sistema de educação a distância como meio de integração e desenvolvimento para o MERCOSUL.

Rev. GUAL., Florianópolis, v.4, n. 1, p.44-69, jan/abr. 2011 
Com base no exposto, o presente estudo tem o seguinte problema de pesquisa: qual a importância da educação a distância para a construção de um MERCOSUL integrado e com vistas ao desenvolvimento das nações integrantes?

O objetivo deste artigo foi analisar a importância da educação a distância (EAD) como elo de integração e desenvolvimento para os países membros (efetivos) do Mercado Comum do Sul.

A reflexão que é feita sobre a importância da educação a distância com elo de integração e desenvolvimento para os países do MERCOSUL, mostra-se relevante por tratar de um tema em grande expansão no mundo e, mais recentemente no MERCOSUL e por considerar que as características desse sistema de ensino podem contribuir efetivamente com os elementos contemplados pelos objetivos do trabalho (integração e desenvolvimento), além de permitir uma maior interação entre os atores envolvidos na educação (alunos, professores, servidores) por meio de uma plataforma on-line.

Estudos que tratem exclusivamente da EAD no MERCOSUL ainda são poucos frente à estudos avançados que envolvem o sistema de educação presencial, caracterizando este estudo, como de fundamental importância para pesquisas sobre o EAD no Mercado Comum do Sul.

O presente trabalho organiza-se da seguinte forma: além desta seção de caráter introdutório, onde apresenta-se o objetivo de estudo, o trabalho é composto por sete seções. A segunda seção trata da educação a distância, onde busca-se conceituar a EAD, apresentar os principais projetos dessa modalidade de ensino no mundo e qual impacto no sistema em alguns países do mundo. Na seção três é descrito o tipo de estudo que envolve este artigo e os procedimentos metodológicos. Na seção quatro são apresentados dados e indicadores sobre os países do MERCOSUL e a situação da educação nesses países. A quinta seção busca discutir as perspectivas da EAD no MERCOSUL. A sexta seção, os resultados da reflexão são apresentados, destacando algumas vantagens do sistema para os países membros, bem como a importância da EAD para o MERCOSUL. A seção sete trata das considerações finais deste trabalho e por último são apresentadas as referências bibliográficas, na seção oito.

\section{REVISÃO DA LITERATURA}

\subsection{Educação a distância}

Rev. GUAL., Florianópolis, v.4, n. 1, p.44-69, jan/abr. 2011 


\section{A EDUCAÇÃO A DISTÂNCIA COMO ELO DE INTEGRAÇÃO E DE DESENVOLVIMENTO PARA OS INTEGRANTES DO MERCOSUL}

\subsubsection{Conceito: educação a distância}

$\mathrm{Na}$ literatura existem diversas nomenclaturas e definições para a educação a distância, conforme pontuado por Aretio (2002). Para o autor, a educação a distância é como um sistema multidirecional no âmbito da comunicação, baseando-se em ações sistemáticas e conjuntas de recursos didáticos, com apoio organizacional (gestores, professores, técnicos) e de tutoria. Como recurso didático, Ronca (2003) lista desde o material impresso até o rádio, televisão, chegando, mais recentemente, o computador, proporcionado pelo desenvolvimento tecnológico.

Corroborando com os autores, Moore e Kearskey (2007) discorrem em sua obra que a educação a distância envolve uma natureza multidimensional, por isso a dificuldade em uma definição precisa. Contudo, quanto a definição, a Associação Brasileira de Educação a Distância (ABED, 2010) considera que há um consenso mínimo em torno da idéia de que EAD é a modalidade de educação em que as atividades de ensino-aprendizagem são desenvolvidas majoritariamente (e em bom número de casos exclusivamente) sem que alunos e professores estejam presentes no mesmo lugar à mesma hora.

Quanto à terminologia, os autores argumentam que ela é variável e causa confusão quanto tenta-se definir a educação pelo tipo de tecnologia utilizada. Dentre os diversos nomes ou terminologias dadas a esse tipo de sistema, destacam-se: educação por correspondência (antiga expressão) e, uma expressão mais recente, aprendizado eletrônico (e-learning) (MOORE E KEARSKEY, 2007).

Interessante observar que as terminologias representam o próprio histórico e evolução do sistema de educação a distância. Associados à essas terminologias e ao termo educação a distância, existem ainda a expressão universidade aberta (Open University), amplamente utilizada pelo mundo.

\subsubsection{Pioneirismo na Educação a Distância e principais projetos de EAD no mundo}

Apesar de estudos históricos e pesquisa referendada, é possível encontrar na literatura relatos de educação a distância na época da Platão (348/347 a.C.). Analisando dados mais precisos, segundo Moore e Kearskey (2007) o correio foi a primeira forma de educação a distância no mundo. Assim, na década de 1880 já era possível estudar em casa ou no trabalho, com as instruções enviadas pelas instituições de ensino. Pelo menos dois acontecimentos 


\section{A EDUCAÇÃO A DISTÂNCIA COMO ELO DE INTEGRAÇÃO E DE DESENVOLVIMENTO PARA OS INTEGRANTES DO MERCOSUL}

influenciaram a boa aceitação do novo sistema de ensino: "a invenção de serviços postais baratos e confiáveis" e a "expansão das redes ferroviárias" (MOORE E KEARSKEY, 2007, p. 25).

A partir de então, vários institutos passaram a oferecer cursos a distância. Ainda segundo os autores, a Chautauqua Correspondece College, foi a primeira instituição a oferecer um curso de educação superior, rebatizado em 1883 (dois anos após a fundação) para Chautauqua College of Liberal Arts e foi autorizado pelo Estado a conceder diplomas e graus de bacharel por correspondência.

Essas iniciativas fazem parte da primeira geração do ensino a distância, caracterizando-a. A segunda geração foi marcada pela transmissão por rádio e televisão, a terceira geração pelo Projeto Mídia de Instrução Articulada (Articulated Instructional Media Project) que tinha o objetivo e agrupar/articular várias ferramentas de comunicação e pelo o surgimento da Universidade Aberta, no governo britânico. A quarta geração foi composta pela teleconferência e a quinta geração, cujas aulas são baseadas em computadores e na rede mundial de internet. Acredita-se que ainda existam algumas características das antigas gerações na atual, visto todo o processo de evolução e aprendizado.

Neste sentido, vários projeto e iniciativas são destaques no mundo, conforme descreve Schlickmann ET. AL. (2008). No estudo, o autor destaca as seguintes instituições de ensino superior a distância: na África, a University of South Africa e a University Of Lagos; na América do Norte, a Empire State College e a Tele Université; na América Latina, a Universidad Nacional Autónoma de México, Universidad Nacional Abierta y a Distancia e a Universidade Aberta do Brasil; na Ásia Indira Gandhi National Open University e a Korea National Open University; na Europa, a Open University e a Universidade Aberta de Portugal; na Oceania University Of Otago e a Open Universities Australia.

Muitas dessas instituições são pioneiras do ensino a distância, como a University of South Africa fundada em 1873. A Indira Gandhi National Open University, fundada em 1985, possuía em 2007 um milhão e meio de alunos na Índia e possuía cobertura em trinta e cinco países. A Korea National Open University, por sua vez, também em 2007, em um projeto das Organizações das Nações Unidas para a Educação, a Ciência e a Cultura (UNESCO), obteve destaque no mesmo, cujo objetivo era o desenvolvimento das universidades a distância do

Rev. GUAL., Florianópolis, v.4, n. 1, p.44-69, jan/abr. 2011 


\section{A EDUCAÇÃO A DISTÂNCIA COMO ELO DE INTEGRAÇÃO E DE DESENVOLVIMENTO PARA OS INTEGRANTES DO MERCOSUL}

leste asiático. Moore e Kearskey (2007) ainda apresentam outros casos no EAD, como: China e Turquia.

$\mathrm{Na}$ China, um país de grandes dimensões e de grande população (mais da metade da população vivem em zona urbana), os autores argumentam que nesse caso, não é surpresa o crescimento que a educação a distância teve no país. No ano de criação do sistema nacional de universidades por rádio e TV (RTVUS), em 1979, 400 mil alunos se matricularam nas universidades em todo o país. Após 1986, com o inicio das transmissões dos programas educacionais via satélite e com a criação de outras instituições de ensino, a carga horária anual de transmissão em canais exclusivos, chegava a nove mil horas. Resultados consideráveis continuam sendo alcançados na China. Considerando a variação percentual entre os anos de 1999 e 2002, o número de formandos, o número de iniciantes, o número de matriculados e de colaboradores, o crescimento observado é, respectivamente: $62,96 \%$; $192,85 \% ; 203,68 \%$ e 20,60\% (MOORE E KEARSKEY, 2007). Esses programas beneficiaram inicialmente a população rural com cursos voltados para a agricultura e professores de escolas primárias e de ensino nédio.

Na Turquia a importância para a educação a distância é tão grande que os alunos que não obtiveram média suficiente (em um exame nacional padronizado) para ter acesso às universidade presenciais, ingressam na Open Education Faculty de Anadolu, vinculada à Anadolu University, uma das maiores de todo mundo. É importante destacar que o ingresso na sistema aberto da Anadolu não é sinônimo de má qualidade, pelo contrário. Os alunos têm acesso ao material didático via jornais, vídeos, programas de TV e rádio, internet e ainda contam com um centro de tutoria, que esclarece as dúvidas dos alunos por meio de telefone, e-mail e fax. Atualmente, a Anadolu University tem 12 faculdades, sendo 3 a distância e o número de alunos na modalidade EAD é de 1.507.047, vinculados às faculdades de Administração, Economia e Educação Aberta (ANADOLU, 2010). Ainda segundo a instituição, ela faz parte do grupo de megauniverisdades do mundo, ou seja, instituições de ensino a distância que atendem a mais de 100.000 alunos (SOUSA, 1996).

Destaca-se ainda, no cenário mundial, a Universidad Libre a Distancia - UNED, criada na década de 70 na Espanha. Segundo dados da própria instituição, a UNED é maior universidade do país com mais de 160.000 alunos (UNED, 2010). Além de estar presente em centros por toda a Espanha e vários países do mundo, como Brasil e Argentina. Somando a 
esses centros, o idioma oficial, espanhol, tem proporcionado a instituição de ensino uma grande expansão, atraindo estudantes de todo mundo. Destaca-se ainda os programas de mobilidade acadêmica internacional da UNED, que por meio de editais proporciona o intercâmbio de alunos da instituição.

Tratando de blocos econômicos, a União Européia (UE) estimula alguns projetos na área da educação. Dentre eles o programa eLearning, que dentre as ações e objetivos está a criação da rede européia de escolas (European Schoolnet - EUN), assim como a Rede de Formação de Professores (Thematic Network on Teacher Education In Europe - TNTEE). A $E U N$ tem por objetivo o fomento à inovação no ensino e aprendizagem aos seus atores envolvidos. A rede é composta por 31 Ministérios da Educação da Europa. A TNTEE tem como objetivo a formação de professores abordando a perspectiva transnacional e multilíngüe. O programa eLearning, não tem por objetivo criar novos processos ou repetir outras iniciativas. Busca-se articular as diferentes ações dos países membros da União Européia e integrar as tecnologias da informação e da comunicação (TIC) nos sistemas de educação do bloco (UE, 2010).

Tais ações são oriundas de um longo processo, que culminou com o Processo de Bolonha, que busca o estabelecimento de uma Área Européia de Ensino Superior, ou seja, a construção de um sistema de educação superior convergente entre todos os países do bloco (UE, 2010; LUZ, MELO, ANGELO, 2005). É clara a forma como a UE trata a educação; como elemento estratégico, buscando tornar os povos educados para viver e trabalhar na sociedade do conhecimento. A base virtual, logo, ganha destaque, dado as vantagens que oferece (UE, 2010).

\subsubsection{O impacto da EAD nos países do mundo}

Conforme descreve Moore e Kearskey (2007) é evidente que a educação e, conseqüentemente, a modalidade a distância, exerceram e exercem papel fundamental no desenvolvimento de muitos países. Na China, o crescimento do PIB (nos últimos anos) foi superior a $50 \%$, onde, associados com outros tipos de investimento do governo chinês, a educação foi considerada com um dos elementos de alavancagem da economia. Não nega-se, que ainda existem algumas mazelas sociais no país, mas o investimento em educação foi e continua sendo decisivo. Segundo relatos de um dos profissionais de maior destaque no 
Brasil, apresentado em um fórum internacional sobre inovação e empreendedorismo, realizado em 2010, a China, em idos dos anos 70-80, reuniu um grupo de profissionais e cientistas de todo o mundo, para debater sobre diversos assuntos sobre a China. Quem sabe, não foi desta reunião que tenham saído as diretrizes de crescimento da China?

Outro impacto positivo e contundente da educação no mundo foi na Coréia. Neste país a educação vai além da simples formação da população. O país vê a educação como elemento de trabalho, no sentido de formador de conhecimento. Desta forma, o trabalhador deixa de ser parte de um processo e passa a agregar valor ainda maior ao produto. Percebe-se, ainda, a importância que a educação teve e têm no país, por meio da declaração da Comissão Presidencial da Reforma da Educação, em 1997: “[...] um Estado de bem-estar social voltado à educação - uma sociedade de educação aberta e permanente, a fim de permitir a cada pessoa acesso igual e fácil à educação em qualquer tempo e lugar" (MOORE e KEARSKEY, 2007, p. 281).

Segundo apresentado neste artigo, na Turquia como não há vagas suficientes para atender demanda de alunos para ingresso no ensino superior, foi incentivado o ingresso no ensino a distância. Nos casos apresentado fica evidente que os países consideram e desenvolvem ações para educação no tocante à acessibilidade ao ensino de qualidade. Os resultados são observados em alguns indicadores, como o PIB, apresentado no gráfico 01.

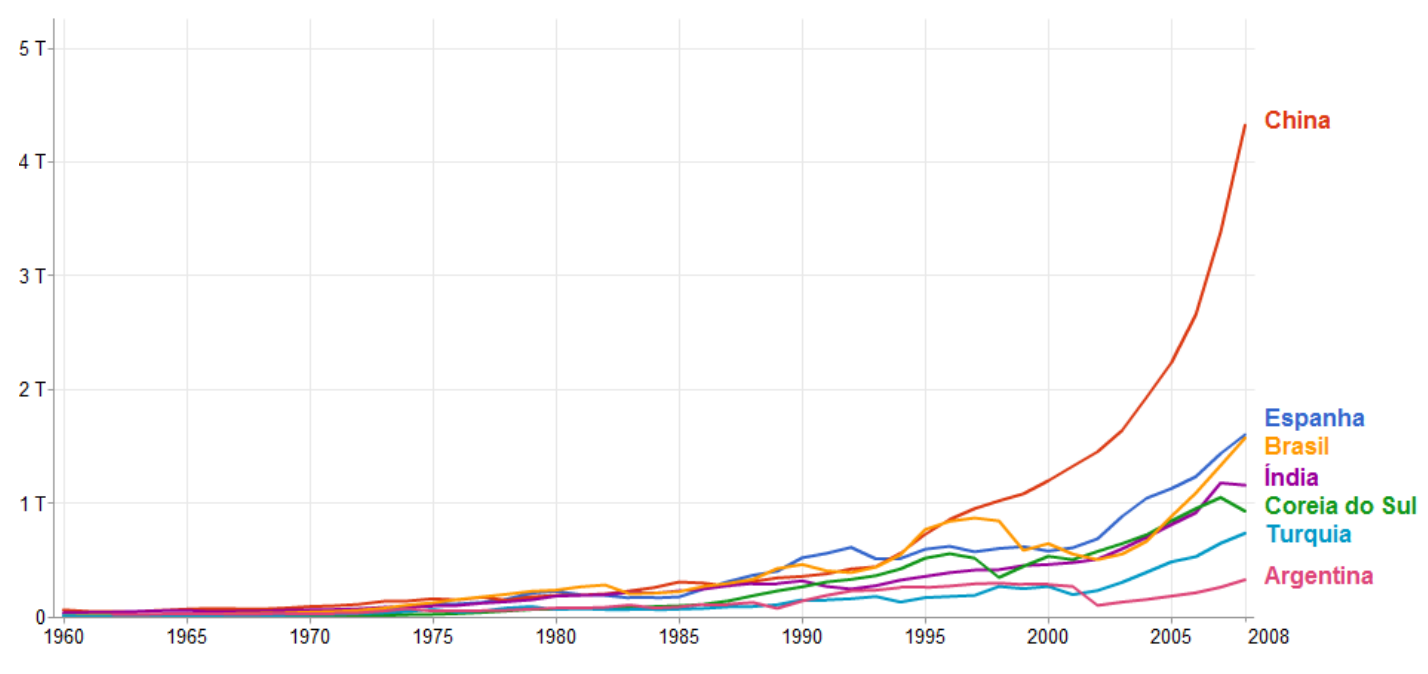

Gráfico 01 - Crescimento do PIB (em US\$)

Fonte: The World Bank (2010) 
Analisando dados do Banco Mundial, percebe-se o crescimento vertiginoso do PIB a partir da década de 80 em diversos países do mundo. Obviamente, o crescimento observado faz parte de uma série de investimentos por parte dos governos, sendo a educação elemento chave para o resultado apresentado.

Tal crescimento está associado com a evolução da taxa de escolarização da população, observado no Gráfico 02.

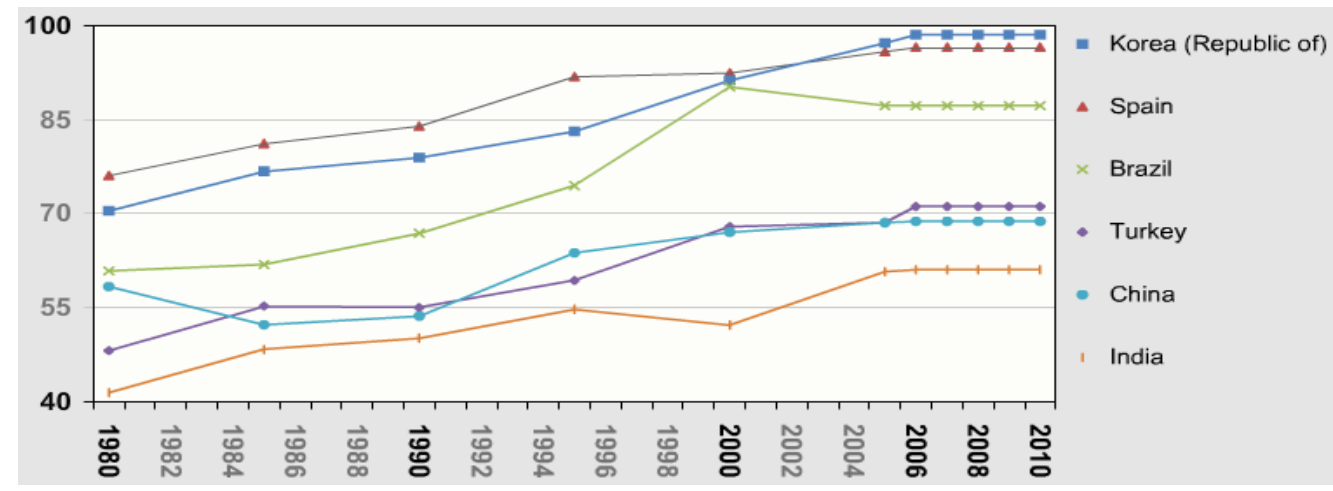

Gráfico 02 - Taxa de escolarização

Fonte: PNUD (2010b)

Apesar de alguns dos países apresentados (Turquia, China e Índia) apresentarem taxa de escolarização abaixo de $72 \%$, a evolução da mesma foi crescente nos últimos anos. Conseqüentemente, os países que mais investiram em educação (além de outras áreas de investimento), destacam-se no IDH, tendo a Espanha e Coréia do Sul com os melhores indicadores, observado no Gráfico 03.

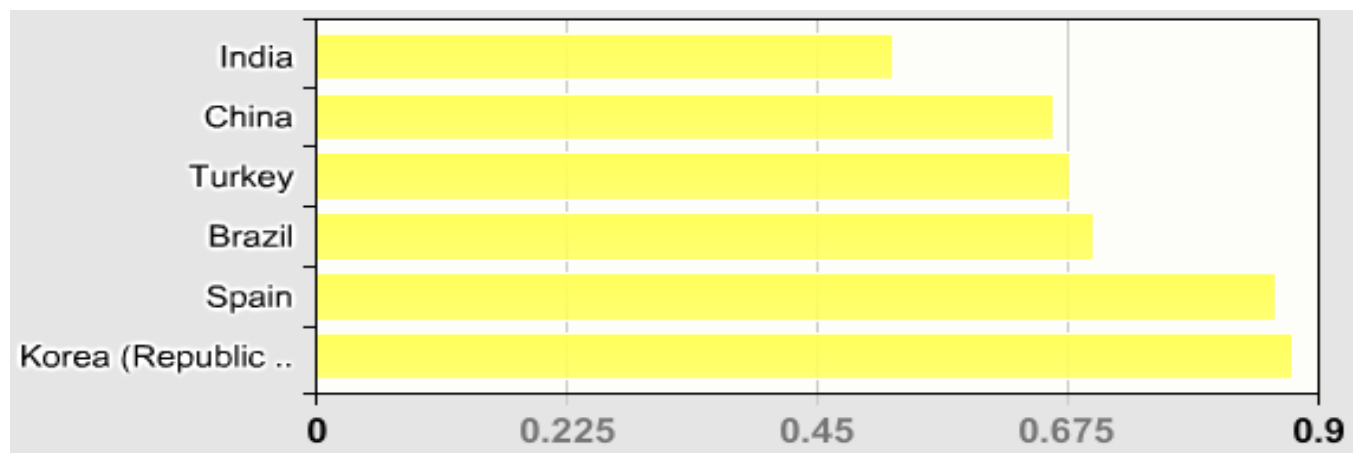

Gráfico 03 - IDH 2010

Fonte: PNUD (2010b)

Diante das práticas de EAD no mundo, observa-se a importância desse sistema para integração, inclusão social/educacional e desenvolvimento das nações. 


\section{PROCEDIMENTOS METODOLÓGICOS}

Inicialmente buscou-se analisar o cenário que envolve a educação a distância no mundo. No segundo momento, dados e informações foram coletadas em: estudos científicos; nas principais organizações internacionais, como o Programa das Nações Unidas para o Desenvolvimento (PNUD), Banco Mundial (The World Bank), International Council for Open and Distance Education; do bloco econômico em estudo (MERCOSUL) e dos países membros; em Instituições de Ensino Superior do MERCOSUL e do mundo e, em projetos semelhantes desenvolvidos em outros blocos econômicos, com objetivo de captar a importância do ensino a distância para o crescimento das nações.

Tais dados são necessários para ordenar as idéias, contrapor argumentos e, principalmente, obter uma nova perspectiva para a educação a distância no contexto do MERCOSUL, como meio de integração social, cultural, econômica e ambiental. Além disso, os dados e informações analisadas contribuem para a reflexão sobre a importância do EAD para o desenvolvimento do bloco.

Com este escopo, as reflexões sobre a importância da educação a distância para o MERCOSUL, como elo de integração e desenvolvimento, pode ser estabelecida neste trabalho.

\section{RESULTADOS}

\subsection{O MERCOSUL: o desenvolvimento e a educação}

Em 2010, os países que fazem parte do MERCOSUL como membros efetivos são: Argentina, Brasil, Paraguai e Uruguai. É importante destacar que a Venezuela aguarda decisão dos Estados Partes, para ser membro efetivo do bloco e, atualmente, é considerado um Estado Associado, assim como a Bolívia, o Chile, Peru, Equador e a Colômbia. Além desses, outros países do mundo têm algum tipo de participação no MERCOSUL, como o Egito, por meio da assinatura do Tratado de Livre Comércio, assinado em agosto de 2010, entre o MERCOSUL e o Egito e o México, que tem status de membro observador (MERCOSUL, 2010a).

Dados do Banco Mundial (THE WORLD BANK, 2010) e dos governos dos países membros do MERCOSUL, mostram que a Argentina tem uma população de 40.276.376 
habitantes (crescimento percentual anual de 0,98), o Brasil tem 193.733 .795 habitantes (crescimento percentual anual de 0,91), o Paraguai tem 6.348.917 de habitantes (crescimento percentual anual de 1,76 ) e o Uruguai tem 3.344.938 de habitantes (crescimento percentual anual de 0,33). No total, são 243.704.026 habitantes nos quatro países.

Ainda segundo dados do The World Bank (2010), o produto interno bruto (PIB) dos países, em 2008, foi de: US\$ 328,465 Bilhões - Argentina; US\$ 1,575 Trilhão - Brasil; US\$ 15,977 Bilhões - Paraguai; US\$ 32,186 Bilhões - Uruguai. Optou-se por dados de 2008, pois a grande maioria dos dados analisados, com base nos indicadores do Banco Mundial (THE WORLD BANK, 2010), estavam correlacionados com esses valores e pelo fato de ser algo consolidado, sem projeções econômico-financeiras, logo, livre de especulações.

Quanto aos indicadores que envolvem a área de comercialização (exportação e importação) apresentam-se os seguintes dados: em relação à importação de produtos e serviços, com base percentual do PIB, o Paraguai apresentou 58,8\% de importação em 2008, seguido por Uruguai com 32,3\%, Argentina com 20,7\% e Brasil com 14,2\%. As exportações, como porcentagem do PIB, segue a mesma classificação de importação: Paraguai com 53,1\%, Uruguai com 28,3\%, Argentina com 24,5\% e Brasil com 14,3\%.

Outro indicador de relevância para as análises e considerações deste artigo é o Índice de Desenvolvimento Humano (IDH). O indicador traça uma medida contemplando indicadores da área de saúde, educação e rendimento dos países, sendo um índice elaborado pelo PNUD (2010). Segundo o órgão, o IDH da Argentina, do Brasil, do Paraguai e Uruguai são, respectivamente: 0,775 ( $42^{\circ}$ lugar no mundo); 0,699 ( $73^{\circ}$ lugar); 0,640 (96 lugar) e 0,765 ( $52^{\circ}$ lugar). O Gráfico 04 ilustra a evolução do IDH, nos países efetivos do MERCOSUL, em um período de 30 anos.

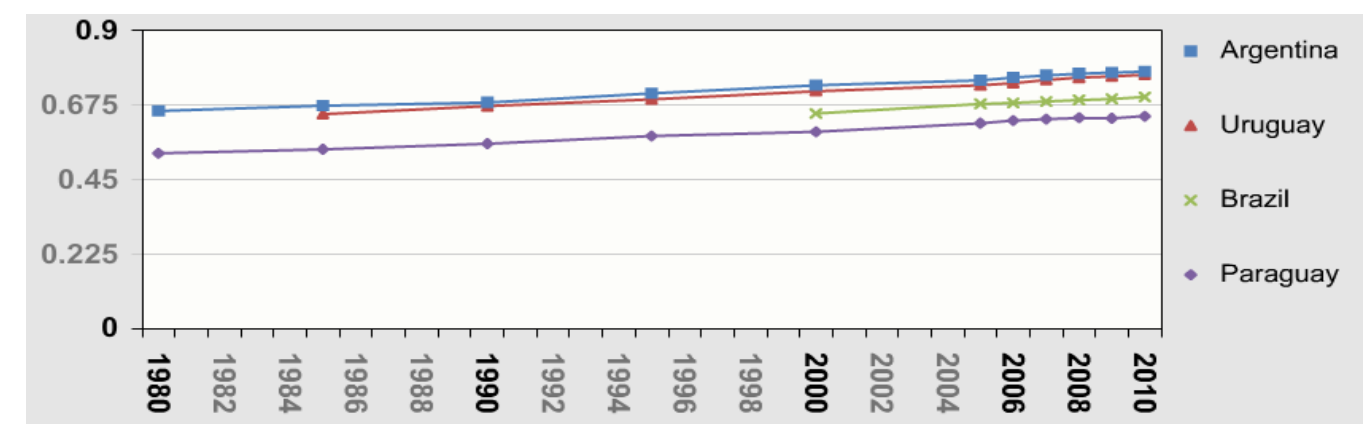

Gráfico 04 - Evolução do IDH nos países membros efetivos do MERCOSUL Fonte: PNUD (2010b) 


\section{A EDUCAÇÃO A DISTÂNCIA COMO ELO DE INTEGRAÇÃO E DE DESENVOLVIMENTO PARA OS INTEGRANTES DO MERCOSUL}

O IDH 2010, publicado em novembro, passou a ter uma nova versão. Assim, o Brasil subiu quatro posições em relação o ano anterior e, junto com a Argentina e Uruguai, estão no grupo que tem um desenvolvimento humano alto. O Paraguai figura no grupo com desenvolvimento humano médio.

Em relação a educação, conforme o documento "Indicadores Estadísticos del Sistema Educativo del Mercosur" elaborado pelo Setor Educacional do MERCOSUL (MERCOSUL, 2010d), o sistema educacional argentino, é organizado em quatro níveis: iniciantes, ensino primário, secundário e superior, onde as crianças iniciam os estudos, em média, aos três anos de idade. O sistema brasileiro é dividido em dois grandes níveis: educação básica, que engloba a educação infantil, fundamental e médio; e o outro grupo que envolve a educação superior. Neste sistema, a criança pode ter acesso a educação, com pouca idade, já que a educação infantil é contemplada com creches, disponíveis para crianças de até três anos de idade. É salutar destacar, que no sistema brasileiro, existem outra formas de educação formal, como: educação especial para portadores de necessidades especiais, educação de jovens e adultos, ensino técnico profissionalizante, dentre outras.

No Paraguai, o sistema é dividido em três partes ou níveis: o primeiro, envolve a educação inicial ou primária e a educação escolar básica; no segundo, o ensino médio e no terceiro nível, corresponde ao ensino superior. As crianças podem ter acesso a educação de forma semelhante ao Brasil, ou seja, por meio de creches. Quando em idade equivalente ao nível escolar básico, o ensino é obrigatório. Outra semelhança do sistema paraguaio com o brasileiro, é a educação de jovens e adultos. No Uruguai, o sistema educacional é dividido em quatro níveis: pré-escolar; ensino fundamental; ensino médio e a educação superior. $\mathrm{O}$ ingresso no sistema educacional uruguaio é feito aos três anos de idade. Apesar dos sistemas terem algumas características em comum, os sistemas tem elementos peculiares, os quais transformam o sistema educacional no MERCOSUL, diversificado (principalmente no ensino superior).

A taxa de alfabetização, segundo Relatório de Desenvolvimento Humano 2009 publicado pelo PNUD (2010a), da Argentina corresponde a 97,60\%, do Brasil a 90,00\%; Paraguai $94,60 \%$ e o Uruguai apresentam uma taxa de $97,90 \%$. Apesar do alto percentual, o país que apresenta o melhor desempenho, o Uruguai, na classificação mundial, fica na quadragésima nona colocação.

Rev. GUAL., Florianópolis, v.4, n. 1, p.44-69, jan/abr. 2011 


\section{A EDUCAÇÃO A DISTÂNCIA COMO ELO DE INTEGRAÇÃO E DE DESENVOLVIMENTO PARA OS INTEGRANTES DO MERCOSUL}

No que se refere a educação de nível superior, em todos os países a oferta é gratuita pelo governo federal e existem as instituições privadas. A Tabela 01 apresenta dados sobre as Instituições de Ensino Superior (IES), Universidades, nos países do MERCOSUL. O objetivo da mesma é apresentar de forma breve a educação superior nos países.

Tabela 01 - As Instituições de Ensino Superior (Universidades) no MERCOSUL

\begin{tabular}{ccccccc}
\hline \multirow{2}{*}{ País } & \multicolumn{3}{c}{ IES Públicas } & \multicolumn{2}{c}{ IES Privada } \\
\cline { 2 - 6 } & IES & $\begin{array}{c}\text { Alunos } \\
\text { Matriculados }\end{array}$ & $\begin{array}{c}\text { Crescimento \% } \\
\text { (Alunos) }\end{array}$ & IES & $\begin{array}{c}\text { Alunos } \\
\text { matriculados }\end{array}$ & $\begin{array}{c}\text { Crescimento \% } \\
\text { (Alunos) }\end{array}$ \\
\hline Argentina & 48 & 1.283 .482 & $3,3^{1}$ & 57 & 317.000 & $6,4^{1}$ \\
Brasil & 97 & 1.110 .945 & $21,29^{2}$ & 86 & 1.574 .683 & $27,52^{2}$ \\
Paraguai & $2^{3}$ & 60.158 & $18,17 \%^{4}$ & {$[?]$} & {$[?]$} & {$[?]$} \\
Uruguai & $6^{5}$ & 81.123 & $15,68^{6}$ & $13^{5}$ & 16.076 & $89,62^{6}$ \\
\hline
\end{tabular}

Fonte: ME Argentina (2010); MEC Brasil (2008); MERCOSUL (2010b, p. Notas: 223-224), MEC Uruguai (2010), (GPEEC, 2010a,b)

${ }^{1}$ Variação percentual entre 1998-2008.

${ }^{2}$ Variação percentual dos anos de 2002-2008, considerando o número de alunos matriculados.

${ }^{3}$ Nas pesquisas somente 2 IES (Universidad Católica e Universidad Nacional de Asunción) foram apresentadas no anuário estatístico do GPEEC (2010a,b).

${ }^{4}$ Variação percentual entre 2004-2008.

${ }^{5}$ Estudo analítico comparativo MERCOSUL (2010b, p. 223-224).

${ }^{6}$ Variação percentual entre os anos 2000-2008.

Na tabela é possível observar o crescimento que a educação apresentou nos últimos anos. Em relação aos dados do Paraguai, no momento da pesquisa, houve limitações em ter acesso as informações sobre as IES, sendo que tal situação já foi observada em outros estudos (USA, 2010). Logo, não foi possível aferir, neste breve estudo, o número de IES públicas e privadas e, no caso dessas, o número de alunos e o crescimento percentual. Os dados apresentados, obtidos no Anuário Estadístico del Paraguay (GPEEC, 2010), referem-se apenas a Universidad Católica e a Universidad Nacional de Asunción, configurando-se como duas das IES de maior relevância e importância para o país.

Apesar da dificuldade apresentada, é possível observar que o Paraguai segue uma tendência de crescimento em relação ao número de alunos matriculados, tal crescimento observado nos demais países do MERCOSUL. Porém, destaca-se que não é possível aferir no nível de qualidade de todas as IES do bloco. 


\section{A EDUCAÇÃO A DISTÂNCIA COMO ELO DE INTEGRAÇÃO E DE DESENVOLVIMENTO PARA OS INTEGRANTES DO MERCOSUL}

Na Argentina, além das 48 IES públicas e das 57 privadas, destaca-se a existência de uma Universidade de Bologna e a Facultad Latinoamericana de Ciencias Sociales FLACSO. No Brasil, o crescimento da educação no ensino superior, principalmente nas IES privadas, está relacionado aos investimentos do governo brasileiro em programas de inserção da população em IES privadas, em que os alunos atendidos pelos programas, recebem benefícios e incentivos para os estudos. No Uruguai, o sistema de ensino superior, segundo MERCOSUL (2010c), das 19 instituições de ensino, 5 são universidades (das quais apenas a Universidad de La República é pública) e 9 são institutos universitários. Corroborando com essa afirmação, sobre o sistema uruguaio Contera (2008, p. 533) discorre

La educación terciaria en Uruguay comprende a la educación superior: Universidad pública y Universidades e Institutos Universitarios privados, y un grupo heterogéneo de ofertas de educación terciaria no universitaria constituido por Institutos de Formación Docente, cursos técnicos dependientes del Consejo de Educación Técnico-Profesional y Escuelas y Centros dependientes de Ministerio.

O crescimento observado é apenas uma fração do desafio que envolve a educação nos países do MERCOSUL. Segundo o Relatório de Monitoramento Global 2010 (Educación para Todos - El Informe de Seguimiento) das Organizações das Nações Unidas para a Educação, a Ciência e a Cultura (UNESCO, 2010), que apresenta dados sobre educação relacionando-os ao projeto "Educação para Todos", o resultado do MERCOSUL apresenta-se de forma não homogênea, entre os países.

A Argentina e o Uruguai foram classificados, respectivamente, na trigésima oitava e trigésima nova colocação, caracterizando-se com Índice de Educação (IDE) alto. Paraguai e Brasil foram classificados com IDE médios, ocupando, respectivamente o setuagésimo segundo e octogésimo oitavo lugar. Ainda segundo o relatório, a Argentina e Uruguai estão no caminho certo para a consolidação das metas de acesso à educação de qualidade. Já o Brasil e Paraguai, estão no grupo que apresentam resultados mistos e precisam de maior investimento (não apenas financeiro).

No caso da educação, com o desenvolvimento e crescimento dos países e com a concretização dos objetivos estabelecidos para o projeto "Educação para Todos", apesar dos riscos de não efetivação dos mesmos, a demanda pelo ensino superior deve crescer ainda mais. Faz-se necessário um projeto integrado no MERCOSUL, para que o atual cenário possa 


\section{A EDUCAÇÃO A DISTÂNCIA COMO ELO DE INTEGRAÇÃO E DE DESENVOLVIMENTO PARA OS INTEGRANTES DO MERCOSUL}

ser alterado positivamente. Destaca-se, então, a educação a distância a como mais um sistema educacional de contribuição para o desenvolvimento dos países.

Assim, os dados apresentados nesta seção são de extrema importância para o alcance do objetivo deste trabalho, pois permitirá uma reflexão sobre a integração e desenvolvimento do bloco econômico em estudo.

\subsubsection{Educação a Distância no MERCOSUL}

A educação a distância está presente em todo o MERCOSUL (FUNIBER, 2010; UAA, 2010; EVA, 2010; UCALP, 2010; UAB, 2010). Considerando os dados da CREAD - The Inter-American Distance Education (2010), Associação Inter-Americana de Educação a Distância (tradução nossa), a Argentina tem dezesseis instituições inscritas, o Brasil dez IES cadastradas e o Paraguai tem duas universidade cadastradas. As iniciativas, claro, não se resumem a essas e contam com o apoio do Setor Educacional do MERCOSUL, que possui um grupo de trabalho composto por especialistas em educação a distância.

Destaca-se neste estudo, a Universidad Católica de La Plata e Universidad Abierta Interamericana (Argentina), a Universidade Aberta do Brasil (Brasil), Universidad Autónoma de Asunción (Paraguai) e a Universidad de La Republica (Uruguai). A exceção da Universidade Aberta do Brasil que é um sistema integrado por universidades públicas para a oferta de cursos de nível superior (UAB, 2010), as demais instituições oferecem cursos na modalidade a distância atendendo as demandas do mercado. A Universidad Abierta Interamericana (Argentina), em 2008, possuía 18.822 alunos matriculados, com taxa de crescimento de 9,4, entre os anos de 1998 e 2008 (ME, 2010). No Brasil, em 2008 eram 115 IES que ofereciam cursos de graduação a distância e 727.961 estudantes matriculados.

A Universidade de Asunción, única a ter dados divulgados no site da instituição, é a primeira universidade a ofertar cursos nessa modalidade e possui cinco mil alunos da faculdade (UAA, 2010). Além da Universidade de Asunción, destaca-se que o Paraguai tem investido em EAD. Em 2007, segundo DGEEC (2010) 63.596 estudantes de nível médio estavam em sistema EAD.

A Universidad de La Republica (Uruguai) disponibiliza um espaço virtual de aprendizagem (EVA, 2010) que é utilizado pelos alunos/professores da universidade. Outro projeto que envolve a educação a distância é a Plataforma de EAD Uruguay Agroalimentario 
Al Mundo, que tem como objetivo transferir as experiências e práticas de sucesso no setor agroalimentar do Uruguai por meio do EAD. Desde o início do projeto, em 2007, foram realizados 30 cursos com a participação de mais de 600 pessoas de 15 países latinoamericanos (FRIDA, 2010).

Ainda que parcial a rápida contextualização panorâmica, apresentada nos parágrafos anteriores, é possível perceber que a educação a distância no MERCOSUL segue a tendência mundial de crescimento, como ferramenta de inserção educacional, social e de desenvolvimento. Ademais, os membros do bloco econômico encontram-se em fase de crescimento em vários setor, fazendo crescer a exigência por mão de obra qualificada. Um bloco com dimensões continentais necessita de um sistema que eduque a população para tais desafios e oportunidades.

Atualmente, conforme apresentado, o principal meio de difusão da educação a distância é por meio da internet. No gráfico 05 , abaixo é possível perceber o acesso à internet pela população. Se por um lado o número de usuários cresceu rapidamente entre o ano de 2000 e 2008, o percentual da população com acesso a rede mundial de computadores ainda é baixo. O Uruguai, país com melhor desempenho neste quesito, apenas 40,2\% da população tem acesso a internet; no Brasil, o percentual é de 37,5\%; a Argentina tem 28,1\% e o Paraguai tem apenas 14,3\%, usuários de internet como porcentagem da população. Em contrapasso, a Coréia do Sul, que se destaca na EAD no mundo, $75,8 \%$ da população tem acesso a internet.

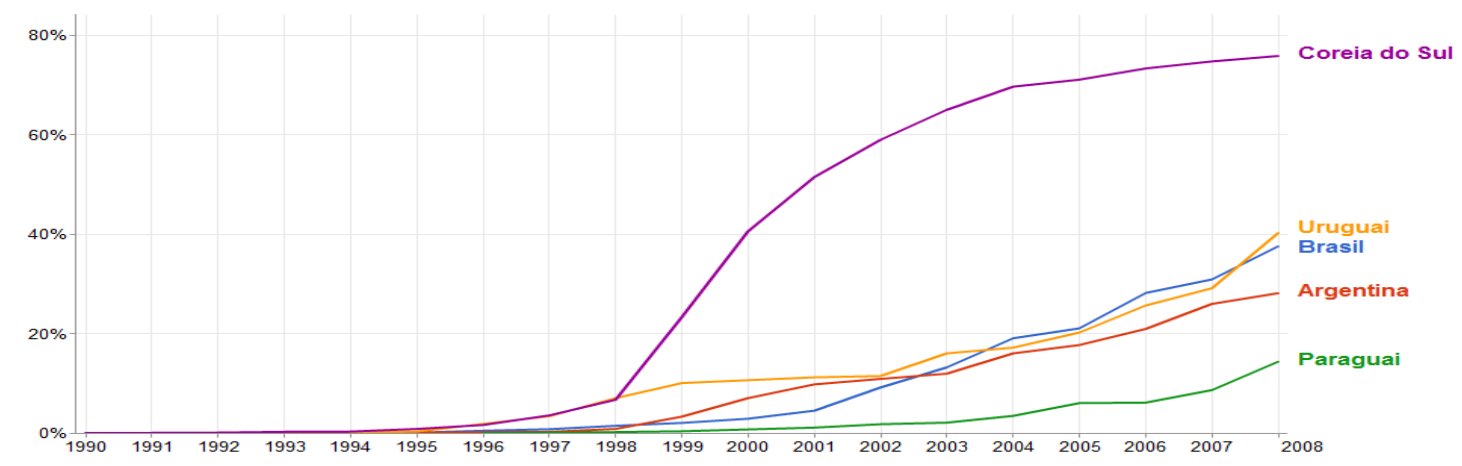

Gráfico 05 - Usuários de internet em \% da população

Fonte: The World Bank (2010)

Desta forma, é necessário que os países do MERCOSUL desenvolvam programas de inclusão digital e que investimentos sejam feitos para atender a demanda da população. 
Observou-se que o debate da educação no MERCOSUL não é recente e que diversas instituições fomentam pesquisas, estudos e projetos envolvendo todos os países do MERCOSUL (membros plenos e associados). Assim sendo, destaca-se a importância de um projeto no sistema de educação a distância integrado para o MERCOSUL. Neste contexto, algumas instituições de ensino com experiência em EAD, podem coordenar um projeto piloto para todo o bloco econômico. A exemplo do processo histórico brasileiro, em que o desenvolvimento do EAD, utilizando os recursos da quinta geração, com objetivo de formar e/ou atualizar professores de ensino básico e médio.

No contexto do MERCOSUL, a Universidade Federal da Integração LatinoAmericana (UNILA) pode exercer um papel fundamental no desenvolvimento de um projeto integrado com ênfase na educação a distância, uma vez que busca a integração latinoamericana por meio do conhecimento. A sua localização estratégica, na fronteia com o Paraguai e Argentina, o seu caráter bilíngüe (português e espanhol), reforçam ainda mais o papel estratégico da IES (UNILA, 2010). Mesmo que ainda esteja em processo de consolidação, a UNILA é desta no cenário sul-americano.

\subsection{O ead como elo de integração e de desenvolvimento para os integrantes do mercosul}

A educação é de fato o grande elemento estratégico e de diferenciação para qualquer tipo de organização e, para as nações do mundo. O investimento em áreas produtivas, como industrias, construção civil, de nada servem se o país não possui mão de obra qualificada. Não se trata apenas de mão de obra treinada/capacitada para atividades repetitivas, configurandose como uma educação fordista (separando a prática da teoria), mas sim, uma educação em que o país e a população (ou aluno) veja o conhecimento como uma forma de agregar valor ao trabalho, conseqüentemente do produto/serviço confeccionado.

Mas, como levar uma educação de qualidade para as regiões remotas dos países membros do MERCOSUL? Como proporcionar esse direito em um país de dimensões continental, como Brasil? Como proporcionar aos países membros do MERCOSUL a integração e o desenvolvimento?

Observou-se neste estudo que a educação a distância é uma alternativa viável para muitos dos desafios que envolvem, em especial, a educação no MERCOSUL e, conseqüentemente, o desenvolvimento dos países. Tal fato foi observado em diversos países 


\section{A EDUCAÇÃO A DISTÂNCIA COMO ELO DE INTEGRAÇÃO E DE DESENVOLVIMENTO PARA OS INTEGRANTES DO MERCOSUL}

no mundo, em condições semelhantes aos dos membros do MERCOSUL e que, ao investiram neste tipo de sistema, alcançaram bons resultados como a Turquia e Coréia do Norte.

Conforme mencionado não se trata apenas de melhorias nos índices ou indicadores. Trata-se de educação para a sociedade do conhecimento, agregando valor ainda maior à educação e aos produtos ou serviços desenvolvidos no país.

Alguns países, membros de outros blocos econômicos, apresentaram nos últimos anos um grande crescimento econômico, social, ambiental, por meio de projetos robustos de educação. O grande diferencial desses países, não está apenas no grande volume de bens e produtos manufaturados, mas sim, no processo de utilização e compartilhamento da educação como elemento estratégico, como no caso da Coréia.

Assim sendo, um projeto de educação a distância como ferramenta de integração, apesar das dificuldades naturais, torna-se um alternativa com alta probabilidade de sucesso. Neste processo inicial, professores ou alunos das Instituições de Ensino Superior de caráter internacional, sediado nos países membros do MERCOSUL, devem ser atores de vanguarda e estimular o desenvolvimento de ambientes virtuais de aprendizagem e integração. Apesar da barreira lingüística, no ambiente virtual, a possibilidade de interação e integração é maior, conforme discorre Moore (2007, p. 185). Somados a essas, outras Instituições que possuem Núcleos de estudos sobre o MERCOSUL, podem contribuir com esse processo, convergindo para uma ampla cooperação inter-institucional.

Outra vantagem e benefício que a EAD pode proporcionar, considerando alguns projetos já existentes no bloco, é a ampliação da mobilidade acadêmica. Apesar de alguns avanços no sentido de reconhecimento de diplomas e cursos, a heterogeneidade dos sistemas de ensino superior do MERCOSUL, a rigidez curricular dos cursos, ainda é uma ação que precisa ser ampliada. A exemplo do Processo de Bolonha, na União Européia, o MERCOSUL tem trabalho visando o avanço da validação e aceitação de diplomas conferidos em países parceiros no bloco. Mais uma vez, neste cenário, a EAD surge como alternativa, uma vez que possibilita uma mobilidade e a flexibilidade acadêmica maior em virtude, por exemplo, da realização de encontros presenciais. Tal evento, neste caso, seria realizado em alternância nos países integrantes do sistema de educação a distância unificado, onde os participantes desse sistema podem participar do evento, fortalecendo o networking e proporcionando encontros presenciais com todos os atores participantes do programa ou projeto. 


\section{A EDUCAÇÃO A DISTÂNCIA COMO ELO DE INTEGRAÇÃO E DE DESENVOLVIMENTO PARA OS INTEGRANTES DO MERCOSUL}

Esse tipo de sistema pode proporcionar a formação de profissionais e de cidadãos internacionais, tendo como premissa o "pensar localmente e agir mundialmente". Desta forma, as ações de desenvolvimento e planejamento da EAD no MERCOSUL devem ser pensadas contemplando as características (culturais, sociais) de cada país. Destaca-se que essa análise deve ser sistêmica, abordando um pensar educacional profundo, ou seja, um pensar para além do holístico.

Tal formação, voltada para uma sociedade de conhecimento, pode proporcionar, ainda, uma série de vantagens e melhorias sociais, econômicas, ambientais (...). Os benefícios sociais podem ser obtidos por meio da melhoria da qualidade de vida da população, da valorização do trabalho, logo, do aumento da renda (benefício também econômico/financeiro). A melhor formação proporcionará bons profissionais, preocupados com o bem-estar da sociedade. Assim, acredita-se que proporcione outro benefício social: a melhoria dos serviços públicos, como saúde, segurança, transporte, lazer, esporte e, claro, a educação.

Logo, um projeto a EAD no MERCOSUL deve envolver profissionais de todos os níveis educacionais (da educação básica a superior). Assim, os formadores estarão alinhados com as perspectivas do projeto, aplicando nas suas aulas/formações os princípios/objetivos executados no EAD MERCOSUL.

Quanto aos benefícios econômicos, além daqueles sociais que tem impacto positivamente nesse setor, a EAD no MERCOSUL é uma forma de qualificar professores em níveis globais com baixo custo, uma vez que esse tipo de sistema, aplicado em formações de grande escala, tem baixo custo (muitas multinacionais já investem em projetos de educação a distância, garantindo, além de uma formação continuada e de alta qualidade, baixo custo e uma grande interação entre os funcionários).

Observa-se que, invariavelmente, todas as áreas são impactadas positivamente, com tal projeto. A questão ambiental (meio ambiente) pode ter uma maior preocupação e iniciativa por parte da sociedade, exigindo cuidados (cada vez maiores) com a preservação ambiental. Por conseguinte, por exemplo, as emissões de $\mathrm{CO} 2$ podem tender a diminuição. Outro setor que pode ter benefícios com o projeto são as questões culturais. Por meio do EAD, a população terá meios de conhecer ainda mais os povos vizinhos. Além disso, a interação,

Rev. GUAL., Florianópolis, v.4, n. 1, p.44-69, jan/abr. 2011 


\section{A EDUCAÇÃO A DISTÂNCIA COMO ELO DE INTEGRAÇÃO E DE DESENVOLVIMENTO PARA OS INTEGRANTES DO MERCOSUL}

proporcionado pelo ambiente virtual, facilita o intercâmbio (ou conhecimento) dos costumes e modos de cada país.

É importante destacar, apesar de óbvio, que um sistema de EAD, integrando o MERCOSUL, sozinho, terá dificuldades para efetivação dos benefícios apresentados e de outros não elencados. É necessário um pensar sistêmico em todas as áreas e setores de uma economia. Neste sentido, enfatiza-se que a educação é um dos pilares de sustentação de todas as outras áreas, consequentemente do país e, a EAD, pode proporcionar a integração e desenvolvimento desejados para o MERCOSUL. Sobre tal importância, faz-se menção às palavras de PACHECO (2010, p. 14), onde ressalta que "A educação é uma das principais bases para o crescimento econômico e social de um país" e ao Preâmbulo da Declaração Mundial sobre Educação Superior no Século XXI, em que se evidencia a importância das IES para o desenvolvimento endógeno, genuíno e sustentável, dos países por meio da formação da massa crítica de pessoas qualificadas e cultas, onde destaca-se ainda que o "compartilhar do conhecimento, a cooperação internacional e as novas tecnologias podem oferecer oportunidades novas para reduzir" as disparidades existentes das nações.

Reforça-se, nas palavras acima, que a educação a distância é um dos sistemas de maior relevância que podem proporcionar a integração, em especial os integrantes do MERCOSUL, e o desenvolvimento das nações. Logo, conforme discorre Melo (2009), a educação a distância é um sistema educacional que precisar se mais difundido e popularizado. Essa realidade não se aplica apenas ao Brasil, mas a todo o mundo, em especial ao MERCOSUL.

\section{CONCLUSÃO}

Conforme o objetivo da presente pesquisa, foi realizado um amplo estudo e reflexão sobre a educação a distância e como ela pode influenciar o desenvolvimento dos países. A reflexão possibilitou uma perspectiva macro sobre a educação a distância no MERCOSUL. O tipo de metodologia escolhida para este trabalho mostrou-se pertinente, pois permitiu um amplo resgate e análise dos cenários que envolvem o MERCOSUL. Além disso, o pouco material científico sobre a educação a distância, que trace uma relação entre os quatro países membros do bloco em estudo, sobre integração e desenvolvimento, contribuiu para que o tipo de estudo caracteriza-se com ensaio teórico. 
Assim, este ensaio, sobre a importância da EAD como elo de integração e desenvolvimento para o MERCOSUL, demonstra que os desafios que envolvem o bloco são inúmeros, porém bons resultados foram alcançados pelo bloco. No campo da educação, considerando os dados apresentados na seção quatro, os países apresentaram certa divergência nos índices. Se por um lado, Argentina e Uruguai têm alcançado bons resultados, por outro, Brasil e Paraguai, apesar de resultados regulares, ainda precisam melhorar em vários aspectos no campo da educação e no social.

Fato que os indicadores econômicos apresentados neste estudo não podem ser analisados sob uma ótica micro (detalhada), mas sim em um amplo contexto. Ao apresentar tais dados, objetivou-se obter uma perspectiva de como a educação a distância pode atuar como elo de desenvolvimento e integração entre os povos do MERCOSUL.

No contexto apresentado, a EAD destaca-se como alternativa viável para a melhoria do cenário observado e como elo de integração e desenvolvimento para os países membros do MERCOSUL. Com uma melhor educação, os países membros do MERCOSUL estarão mais aptos a competirem no cenário mundial, maximizando o percentual (em relação ao PIB) das exportações e importações. Já é sabido do papel estratégico e crítico (fator crítico) que a educação tem, logo o investimento neste setor é uma avanço considerável não apenas no meio econômico, por exemplo, mas para todas as áreas do país. Quanto maior o número de pessoas estudando, participando de sistemas de ensino integrado e de qualidade, melhores serão os índices como IDH e IDE.

Destarte, o problema de pesquisa que motivou este ensaio teórico foi respondido na medida em que verificou-se a importância da educação a distância para a construção de um MERCOSUL integrado e desenvolvido.

Conclui-se, portanto, que em um bloco de dimensões continentais, a educação a distância é de extrema importância para o desenvolvimento sustentável e integrado para o MERCOSUL, ou seja, para os países membros do bloco econômico. Grandes são os desafios para a educação, porém o sistema a distância oferece diferenciais e vantagens para um projeto integrado de alta qualidade e baixo.

Rev. GUAL., Florianópolis, v.4, n. 1, p.44-69, jan/abr. 2011 


\section{REFERÊNCIAS}

ABED. Associação Brasileira de Educação a Distância. O que é educação a distância? Disponível em: < http://www2.abed.org.br/faq.asp?Faq_ID=8>. Acesso em: 01 nov. 2010.

ANADOLU. Anadolu University. About the University. Disponível em:

$<$ http://www.anadolu.edu.tr/en/>. Acesso em: 03 nov. 2010.

ARETIO, Lorenzo García. La educación a distância: de la teoría a la práctica. Barcelona, Ariel Educación, 2001.

CONTERA, Cristina. La educación superior en Uruguay. Avaliação: Revista da Avaliação da Educação Superior. V. 13, n. 2, p. 533-554, jul. 2008.

CREAD. The Inter-American Distance Education. Disponível em:

$<$ http://www.schoolofed.nova.edu/cread/institutional.htm>. Acesso em: 03 nov. 2010.

DGEEC. Dirección General de Estadística, Encuestas y Censos (Paraguai). Anuario

Estadístico del Paraguay 2004. Disponível em: <

http://www.dgeec.gov.py/Publicaciones/Biblioteca/Anuario2004/Anuario2004.htm $>$ e $<$ http://www.dgeec.gov.py/Publicaciones/Biblioteca/Anuario2004/Capitulo_3.pdf $>$. Acesso em: 03 nov. 2010a.

. Dirección General de Estadística, Encuestas y Censos (Paraguai). Anuario Estadístico del Paraguay 2008. Disponível em:

$<$ http://www.dgeec.gov.py/Publicaciones/Biblioteca/Anuario2008/Indice\%202008.pdf $>$ e $<$ http://www.dgeec.gov.py/Publicaciones/Biblioteca/Anuario2008/Cap.\%2003-2008.pdf>. Acesso em: 03 nov. 2010b.

EVA. Entorno Virtual de Aprendizaje. Disponível em: < http://eva.universidad.edu.uy/>. Acesso em: 03. nov. 2010.

FRIDA. Fondo Regional para la Innovación en América Latina y el Caribe. Plataforma de EaD Uruguay Agroalimentario al Mundo. Disponível em:

$<\mathrm{http}$ //premiofrida.org/por/projects/view/193>. Acesso em: 03 nov. 2010.

LUZ, Rodolfo Joaquim Pinto da; MELO, Pedro Antônio de; ANGELO, Gilberto Vieira.

Educação superior na América Latina: uma convergência necessária. Revista de Ciências da Administração. V. 7, n.13, jan/jul 2005.

ME. Ministério de la Educación (Argentina), Secretaria de Políticas Universitarias, Directoria Nacional de Coordinación Institucional, Evaluación y Programación Presupuestaria, Coordinación de Investigaciones e Información Estadística. Estadísticas Universitarias: Anuario 2008. Buenos Aires: Coordinación de Investigaciones e Información Estadística (CIIE), 2008. Disponível em: <http://www.mcye.gov.ar/spu/documentos/Anuario_2008.pdf>. Acesso em: 27 out. 2010. 
MEC. Ministério da Educação, Instituto Nacional de Estudos e Pesquisas Educacionais Anísio Teixeira. Resumo técnico: Censo da Educação Superior 2008. Disponível em: < http://200.130.24.14/download/censo/2008/resumo_tecnico_2008_15_12_09.pdf $>$. Acesso em 22 jul. 2010.

MEC. Ministerio de Educación y Cultura (Uruguai), Dirección de Educación. Anuario Estadístico de Educación 2008, 2009. Disponível em:

$<$ http://www.oei.es/pdf2/Uruguay_anuario_estadistico_educacion_2008.pdf $>$. Acesso em: 27 out. 2010.

MELO, Pedro Antônio de; MELO, Michelle Bianchini de; SCHLICKMANN, Raphael. Desafios da educação superior contemporânea: contribuições e tendências da universidade na formação de profissionais para a sociedade. Atos de Pesquisa em Educação. v. 4, no 3 , p.407-431, set./dez. 2009.

MEP. Ministerio de Economía y Producción (Argentina), Secretaría de Política Económica, Instituto Nacional de Estadística y Censos. Proyecciones provinciales de población por sexo y grupos de edad 2001-2015. Buenos Aires: Instituto Nacional de Estadística y Censos (INDEC), 2005.

MERCOSUL. Mercado Comum do Sul. Sobre o Mercosul. Disponível em:

$<\mathrm{http}: / /$ www.mercosur.int $/ \mathrm{t}$ generic.jsp? contentid $=655 \&$ site $=1 \&$ channel $=$ secretaria\&seccion $=2>$. Acesso em 02 out. $2010 \mathrm{a}$.

. Mercado Comum do Sul, Comitê Coordenador Regional do Setor Educacional do MERCOSUL. Ata da II Reunião de Ministros da Educação da República Argentina, República Federativa do Brasil, República do Paraguai e República Oriental do Uruguai. MERCOSUR/RME/Acta No 01/92. Buenos Aires, 1 de junho de 1992. Disponível em:

$<$ http://www.sic.inep.gov.br/index.php?option=com_docman\&task=doc_download\&gid=139 \&Itemid=32>. Acesso em: 29 out. 2010 b.

. Mercado Comum do Sul, Sistema de Informação e Comunicação, Setor Educacional do Mercosul. Estudo Analítico Comparativo do Sistema Educacional do Mercosul (20012005), 2008. Disponível em: < http://www.oei.es/pdfs/25Mercosul.pdf>. Acesso em: 29 out. 2010c.

Mercado Comum do Sul, Setor Educacional do MERCOSUL. Indicadores Estadísticos del Sistema Educativo del Mercosur. Disponível em:

$<\mathrm{http}$ ://www.sic.inep.gov.br/index.php?option=com_docman\&task=doc_download\&gid $=617$ \&Itemid=34> . Acesso em: 02 out. $2010 \mathrm{~d}$.

MOORE, Michael G; KEARSKEY, Greg. Educação a distância: uma visão integrada. São Paulo: Thomson Learning, 2007. 
PACHECO, Andressa Sasaki Vasques. Evasão e permanência dos estudantes de um curso de Administração do Sistema Universidade Aberta do Brasil: uma teoria fundamentada em fatos e na gestão do conhecimento. Florianópolis: UFSC, 2010. 298 p. Tese (Doutorado) Programa de Pós-Graduação em Engenharia e Gestão do Conhecimento, Universidade Federal de Santa Catarina, Florianópolis, 2010.

PNUD. Programa das Nações Unidas para o Desenvolvimento. Human Development Report 2009. Overcoming barriers: human mobility and development. Disponível em: $<$ http://hdr.undp.org/en/media/HDR_2009_EN_Complete.pdf $>$. Acesso em: 25 out. 2010a.

Programa das Nações Unidas para o Desenvolvimento. International Human

Development Indicators. Disponível em: $<$ http://hdr.undp.org/en/data/map/>. Acesso em: 04 nov. 2010 b.

Programa das Nações Unidas para o Desenvolvimento. Ranking do IDH 2010.

Disponível em:

$<$ http://www.pnud.org.br/pobreza_desigualdade/reportagens/index.php?id01=3600\&lay=pde> . Acesso em: 04 nov. 2010c.

RONCA, Antônio Carlos Caruso. Prefácio. In: VALENTE, José Armando; PRADO, Maria Elisabette B. Brito; ALMEIDA, Maria Elizabeth Biaconcini de. (Org.). Educação à Distância via internet. São Paulo: Avercamp, 2003.

SCHLICKMANN, Raphael; ROCZANSKI, Carla Regina Magagnin; AZEVEDO, Paola. Experiências de Educação Supeior a Distância no Mundo. Anais do VIII Colóquio Internacional sobre Gestão Universitária na América do Sul, Assunção. 2008. Disponível em: $<$ http://www.inpeau.ufsc.br/wp/wp-content/BD_documentos/2191.pdf $>$. Acesso em: 27 out. 2010 .

SOUSA, Eda Coutinho B. Machado de. Panorama internacional da educação a distância. Em Aberto, $n^{\circ} .70$, abr./jun. 1996.

The World Bank. Indicators. Disponível em: <http://data.worldbank.org/indicator $>$. Acesso em: 3 nov. 2010.

UAA. Universidad Autónoma de Asunción. Dispoível em:

$<$ http://www.uaa.edu.py/educ_a_distancia/>. Acesso em: 03 nov. 2010.

UAB. Universidade Aberta do Brasil. Disponível em:

$<$ http://www.uab.capes.gov.br/index.php>. Acesso em: 03 nov. 2010.

UCALP. Universidade Católica de La Plata. Disponível em: <http://www.ucalp.edu.ar/>. Acesso em: 03 nov. 2010.

UE. União Européia. Síntese da legislação da UE. Disponível em:

$<$ http://europa.eu/legislation_summaries/education_training_youth/lifelong_learning/index_pt .htm>. Acesso em: 03 nov. 2010. 
UNED. Universidad Libre a Distancia. Disponível em: $<$ http://www.uned.es/> . Acesso em: 03 nov. 2010.

UNESCO. Organizações das Nações Unidas para a Educação, a Ciência e a Cultura. Educación para Todos - El Informe de Seguimiento. Disponível em: <

http://unesdoc.unesco.org/images/0018/001878/187865S.pdf $>$. Acesso em: 23 out. 2010.

UNILA. Universidade Federal da Integração Latino-Americana. Disponível em:

$<$ http://www.unila.edu.br/>. Acesso em: 03 nov. 2010.

USA. United States of America. Library of Congress. Federal Research Division. Country Profile: Paraguay, october 2005. Disponível em:

$<$ http://lcweb2.loc.gov/frd/cs/profiles/Paraguay.pdf>. Acesso em: 03 nov. 2010. 


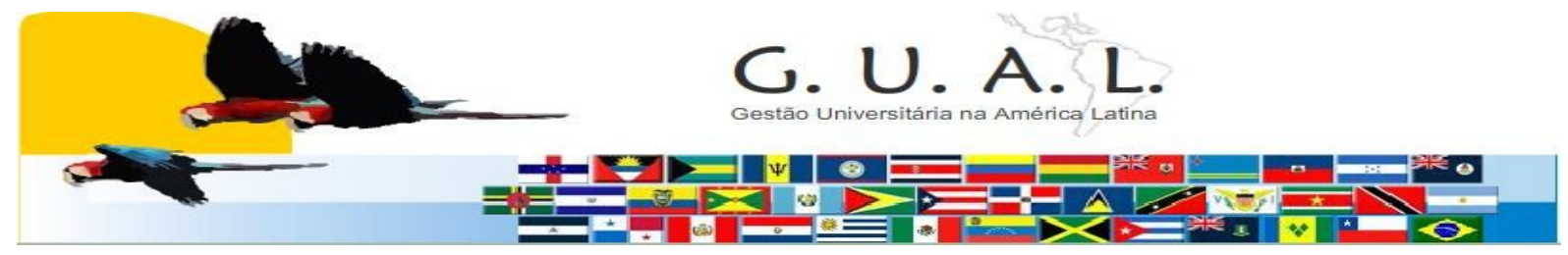

ISSN 1983-4535

\title{
THE DISTANCE EDUCATION AS A LINK INTEGRATION AND DEVELOPMENT FOR THE MEMBERS OF MERCOSUR
}

\author{
Lucas Ambrósio Bezerra de Oliveira, Bachelor \\ lucasambro@gmail.com \\ Universidade Federal do Rio Grande do Norte - UFRN \\ Fernanda Cristina Barbosa Pereira Queiroz, Doctor \\ fernandacbpereira@yahoo.com.broufbp@ufrnet.br \\ Universidade Federal do Rio Grande do Norte - UFRN \\ Jamerson Viegas Queiroz, Doctor \\ jvqjamerson@yahoo.com.brou jvq@ufrnet.br \\ Universidade Federal do Rio Grande do Norte - UFRN
}

\author{
Hélio Roberto Hékis, Doctor \\ hrhekis@hotmail.com \\ Universidade Federal do Rio Grande do Norte - UFRN \\ Ricardo Pires de Souza, Bachelor \\ ripiso@gmail.com \\ Universidade Federal do Rio Grande do Norte - UFRN
}

\begin{abstract}
Education is considered as the most important element to the nations' growth, and therefore a critical factor for their development. Thus, the article wants to analyze the importance of distance education as a bridge of integration and development to MERCOSUR's countries. This is a theoretical essay. Therefore, as parameters to reflection data and information were collected in scientific studies, major international organizations, projects developed in others economics blocs, as well as data obtained in the MERCOSUR countries. The study's results indicate that the stimulus to the creation of an integrated program for expansion of distance education in MERCOSUR is extremely important and has great potential, which may have a huge development. It is known that the program should consider an education that addresses local characteristics, paying attention to the regional and global issues, encouraging, therefore, the citizens' formation with a worldwide commitment. It is concluded that distance education can help to the nations' integration and development, as well as the internationalization of education institutions, through student's exchange, teachers and staff, among other advantages.
\end{abstract}

Keywords: Distance education. MERCOSUR. Development. 